\title{
Feral Pigs, Introduced Mosquitoes, and the Decline of Hawai'i's Native Birds
}

The introduction of mosquitoes, avian pox, and avian malaria to the Hawaiian Islands has had a profound effect on the geographical distribution and population number of highly susceptible Hawaiian honeycreepers, and likely contributed to the extinction of several species. While the mosquito vector (disease-carrier) is most closely associated with human activity, in remote Hawaiian rain forests, feral pigs may be pivotally important to the disease system. Since 1991, USGS scientists have taken a leadership position in identifying the role these diseases continue to play in the decline and extinction of native Hawaiian forest birds and in finding ways to mitigate their impacts.

\section{Hawaiian Birds Imperiled}

Although introduced avian disease may have contributed to the early extinctions of many Hawaiian birds, it is the Hawaiian honeycreepers or Drepanidinae that appear most sensitive to disease. All fifty-seven known species are believed to have evolved from a single finch-like ancestor. Much like Darwin's finches of the Galápagos Islands, honeycreepers are an amazing example of adaptive radiation - the evolution of related species adapted to different ecological niches.

Honeycreepers were once found in the forests from the coast to the timberline and were so abundant that one early naturalist described the sound of their singing in coastal forest as deafening. Unfortunately, more than half of the honeycreeper species are now extinct. Some disappeared before the arrival of Europeans, but most extinctions have occurred since that time. Loss of forest habitat and the introduction of small mammal predators, like the black rat, were probably responsible for extinctions during the 1800s. During the last century, however, introduced mosquitotransmitted bird diseases are thought to have contributed to the extinction of several more species.

Today, these diseases are considered one of the most important factors limiting Hawaiian honeycreeper populations. The greatest density and species diversity of Hawaiian honeycreepers is now found in the highest, coolest, and driest forests where mosquitoes, and avian disease, seldom occur.

\section{Introduced Avian Pox and Avian Malaria}

Avian pox Avipoxvirus and avian malaria Plasmodium relictum are mosquito-transmitted diseases that affect native Hawaiian birds. Although common in wild bird populations on continents worldwide, these bird diseases were absent from isolated islands where mosquitoes did not occur. In the extreme isolation of the Hawaiian Islands, birds evolved in the absence of mosquito-transmitted disease and lost their natural immunity to these common continental pathogens.

Avian pox is a virus that can be efficiently transmitted by mosquito bite. It causes large nodules or lesions, most commonly on the head or feet, that may interfere with feeding or predator avoidance. Avian malaria is similar to human malaria but only affects some bird species. It is caused by a single-celled parasite that depends on a mosquito for transmission to the next bird. In the bird, the parasite destroys red blood cells thereby weakening the bird. Acutely infected birds are inactive, do not feed, and probably succumb to starvation, cold weather, or predation. For some bird species, like the ' $i$ 'iwi (Vestiaria coccinea), malaria infection is almost always fatal.

Avian pox may have arrived in the Hawaiian Islands with migratory birds but avian malaria most likely arrived with the importation of exotic game and cage birds during the first half of the last century. Neither of these diseases, however, could have become so widely established if mosquitoes had not been accidentally introduced to the Hawaiian Islands.

Figure 1. The extant species of Hawaiian honeycreepers found in the wet forests on Hawai'i Island. A: Hawai'i Creeper, Oreomystis mana (endangered); B: 'Akepa, Loxops coccineus (endangered); C: Apapane, Himatione sanguinea; D: Hawai'i 'Amakihi, Hemignathus virens, E: 'I'iwi, Vestiaria coccinea; and F: 'Akiapōlā'au, Hemignathus munroi (endangered). (Photos (C) Jack Jeffrey)
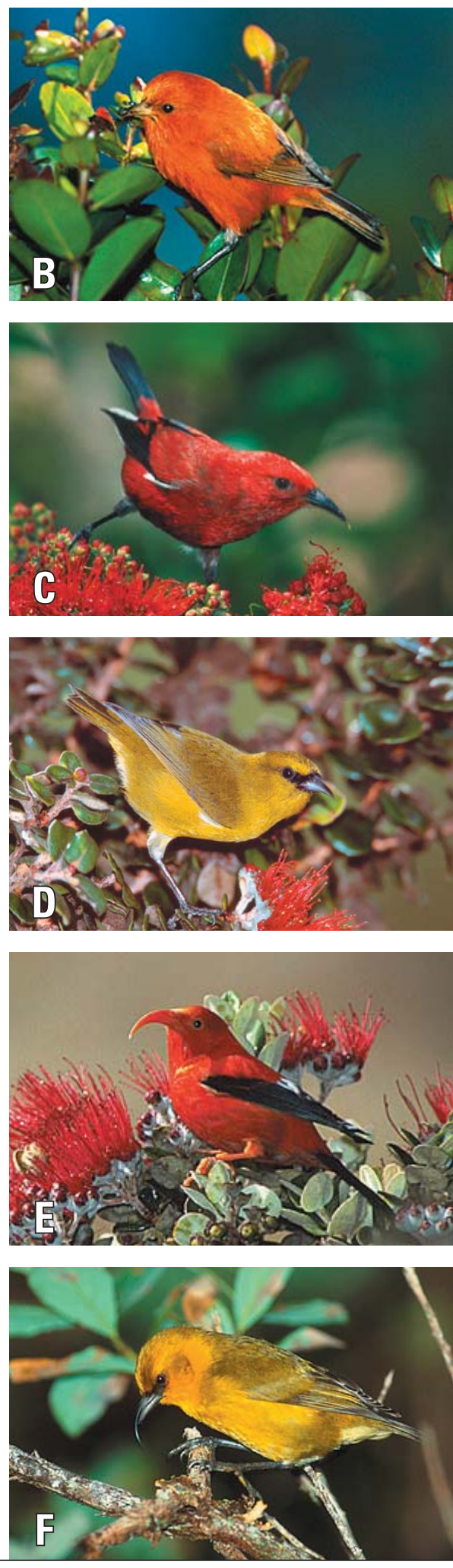


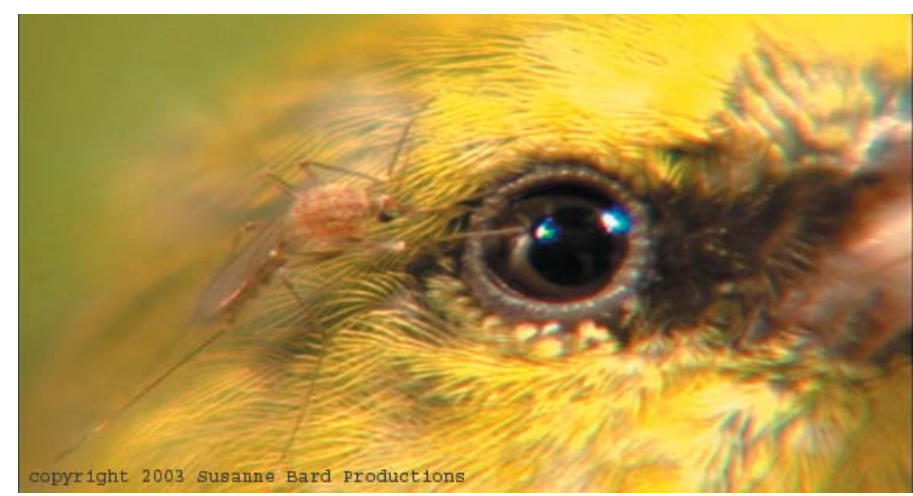

Figure 2. A southern house mosquito (Culex quinquefasciatus) bites an 'amakihi. While continental birds typically defend themselves against blood-feeding mosquitoes, Hawaiian birds are more tolerant of biting mosquitoes and more likely to become infected with disease. Culex mosquitoes feed most actively at night, when birds are roosting.

\section{Paradise Lost: The Southern House Mosquito in Hawai'i}

Though common in most continental areas, mosquitoes are not native to many oceanic islands. The southern house mosquito Culex quinquefasciatus occurs throughout the subtropical and tropical regions of the world. It is often associated with manmade habitats and was spread widely through commerce. It was the first mosquito to arrive in Hawai' $i$, having been introduced in 1826 when, presumably, it was brought ashore in water casks from a ship recently sailed from Mexico. Today, six species of biting mosquitoes can be found in the Hawaiian Islands but only Culex carries avian malaria and, most likely, avian pox.

Field and laboratory research by USGS scientists and collaborators has increased our understanding of the basic biology and vector potential of this mosquito in the Hawaiian Islands. The southern house mosquito is the most widely distributed mosquito in the Hawaiian Islands and can be found from the coast to 6000 feet. Typically, females lay eggs in small, calm bodies of water that are rich in organic nutrients. The filter feeding larvae can complete their development in seven days under optimal nutrition and temperature but may take months to develop under less favorable conditions.

Although the majority of research on the dynamics of introduced avian disease in Hawai' $i$ has been conducted on Hawai'i Island, the results are believed to be applicable to other parts of the archipelago. On the windward side of the island of Hawai' $i$, adult mosquitoes are present year-round at low elevations where adequate rainfall and optimal temperatures allow for multiple generations. There is evidence of year-round disease transmission in these lowlands. At mid-elevations (around 900-1200 meters), adult mosquitoes are seasonally abundant in the late summer. This late summer peak coincides with annual
Figure 4. Larval habitat surveys were conducted on eight sites located on Kaua'i, Maui, and the Island of Hawai'i. Tree fern cavities were the most common available habitat below $1800 \mathrm{~m}$ elevation and were more likely to contain larvae than any other type of aquatic habitat.
Larval Mosquito Habitat in Hawaiian Forests

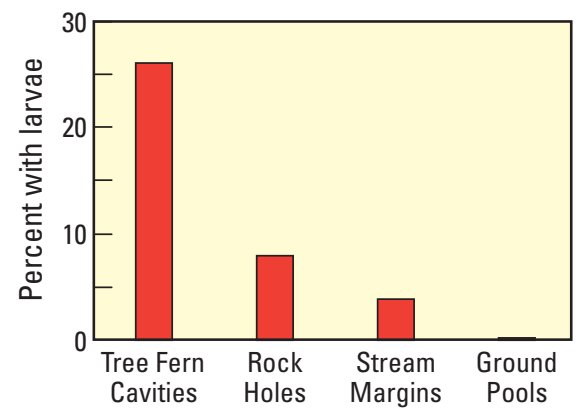

outbreaks of avian malaria. Adult mosquito populations at the highest elevations ( $\geq 1800$ meters) are infrequent, reduced in number, shortlived, and do not appear to transmit avian malaria. Mosquitoes and disease are limited at high elevations by cool year-round temperatures that prolong larval, and inhibit parasite, development.

Mosquito larvae are found in ditches, catch basins, livestock troughs, and any number of artificial containers or water impoundments typical of urban and rural communities. High densities of adult mosquitoes can be produced from the rainwater-filled refuse and poorly-maintained infrastructure common to most areas of human activity. In Hawaiian forests, however, suitable larval mosquito habitat is more limited than might be imagined. Larvae are seldom found in ground pools, bogs or flowing streams but do occur in tree fern cavities and the rock holes and pools of intermittent stream beds.

\section{Feral Pigs Increase Mosquito Abundance}

Although a considerable amount of precipitation falls on the slopes of Mauna Loa, very little water is retained on the surface of its young, volcanic substrates. In these wet forests, mosquito larvae are most commonly found in the cavities of tree fern trunks. Small cavities form naturally through the action of decay but the larger cavities, occupied by mosquito larvae, are created by feral pigs (Sus scrofa). Feral pigs knock over tree ferns, tear through the fibrous and woody outer layers, and eat the starchy pith leaving behind a bowl- or trough-shaped cavity that fills up with rainwater. In forests where tree ferns and pigs occur together, these cavities are the most abundant and productive habitat for larval mosquitoes. Feral pigs increase the numbers of mosquitoes found in the forest.

Feral pigs have been eliminated from much of the Department of Interior (DOI) land in the Hawaiian Islands, but this is not necessarily so on adjacent state or private land. Mosquitoes may disperse up to 2 miles $(3 \mathrm{~km})$ in native forests. Because of this surprising dispersal ability of mosquitoes, small and/or fragmented refuges and parks cannot expect to manage avian disease through feral pig elimination without

Figure 3. A: Culex mosquitoes lay rafts containing approximately 200 eggs in stagnant water. B: Water contaminated with fecal matter or decomposing vegetation can support high densities of larvae. C: Adult mosquitoes rest in crevices and dense vegetation during the day.
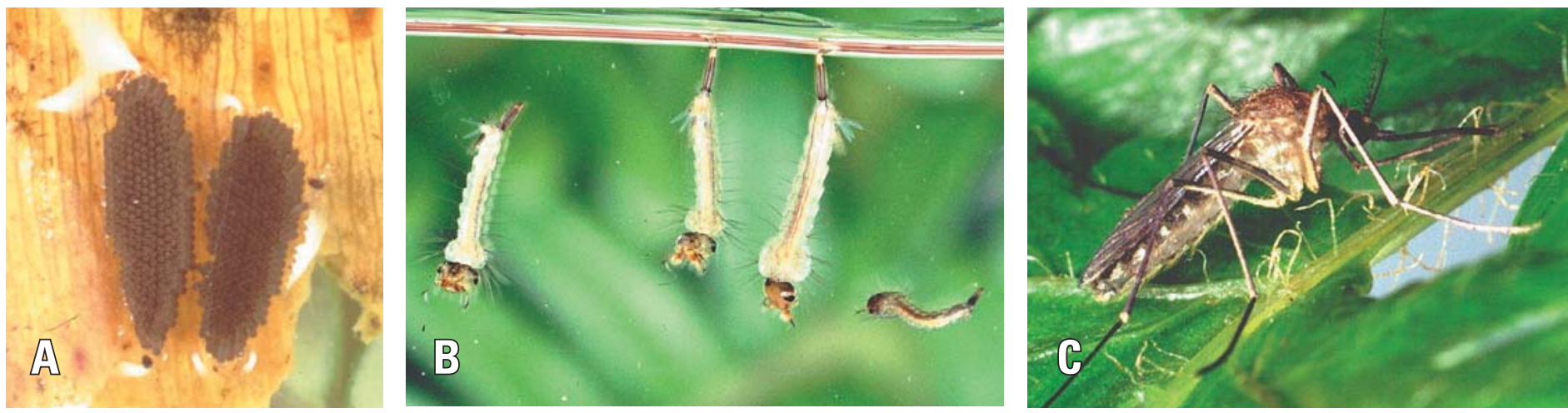
Figure 5. Feral pigs in Hawai'i are the descendants of domestic pigs brought to the islands by European explorers. They are perhaps the most destructive invasive species in Hawaiian wet forests. Their feeding on the starchy cores of native tree ferns creates nutrient-rich, rain-filled cavities that can support hundreds of larval mosquitoes. However, feral pigs are a valued game species in Hawai'i and there are no easy solutions to the destructive relationship between feral pigs, mosquitoes and native birds. (Photos by Dan Lease)
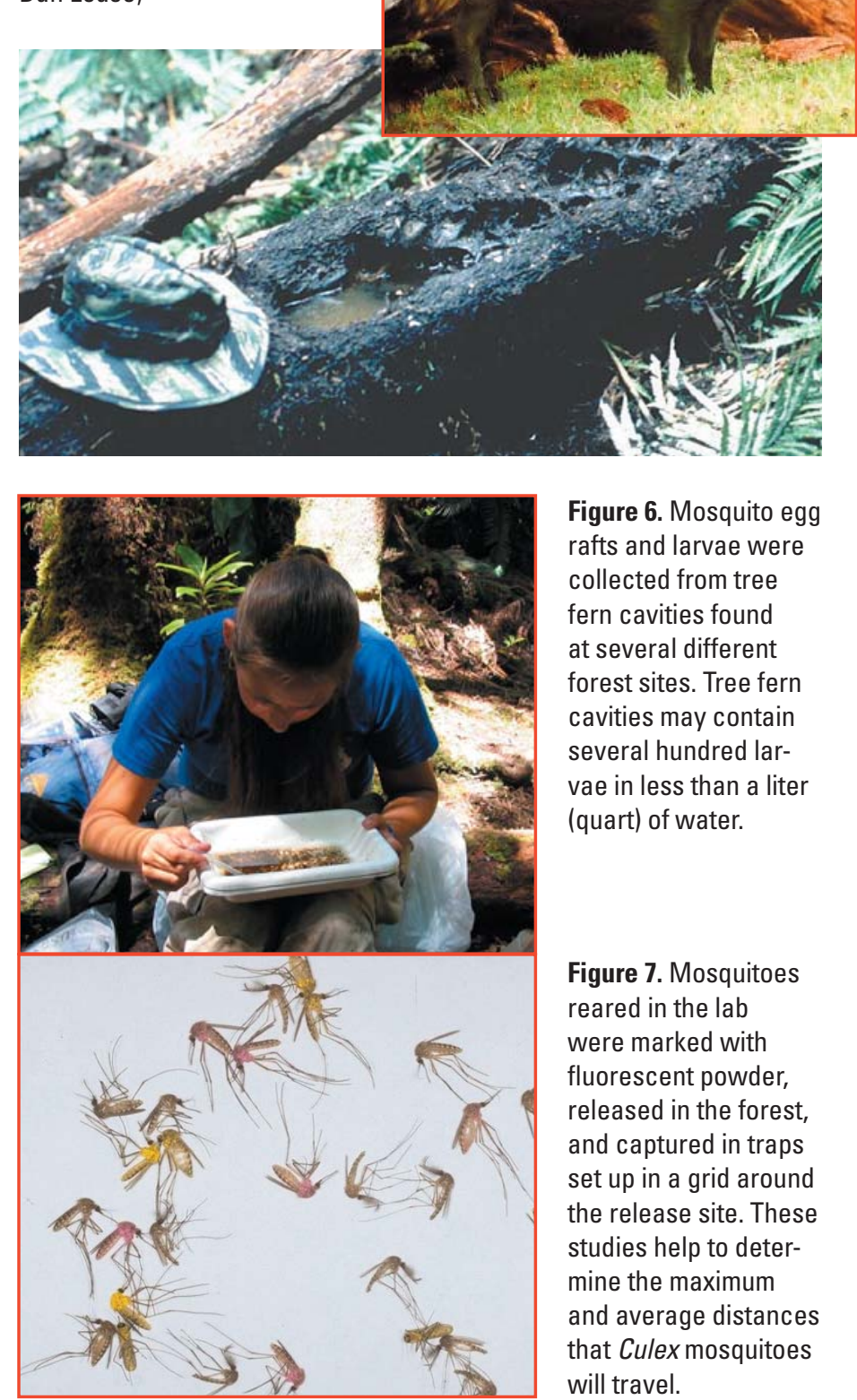

Figure 6. Mosquito egg rafts and larvae were collected from tree fern cavities found at several different forest sites. Tree fern cavities may contain several hundred larvae in less than a liter (quart) of water.

Figure 7. Mosquitoes reared in the lab were marked with fluorescent powder, released in the forest, and captured in traps set up in a grid around the release site. These studies help to determine the maximum and average distances that Culex mosquitoes will travel.

extending control into neighboring lands. There are many obstacles, however, to landscape level feral pig control. Feral pig elimination is expensive and, in many cases, competes with the mandates of state agencies to provide game for recreational hunting.

\section{Source Reduction of Man-Made Larval Mosquito Habitat}

The infrastructure of DOI lands in Hawai' $i$ is not often designed or maintained with mosquito control in mind, and can contribute significantly to mosquito production. Neighboring residential communities and agricultural operations may also produce mosquitoes that will

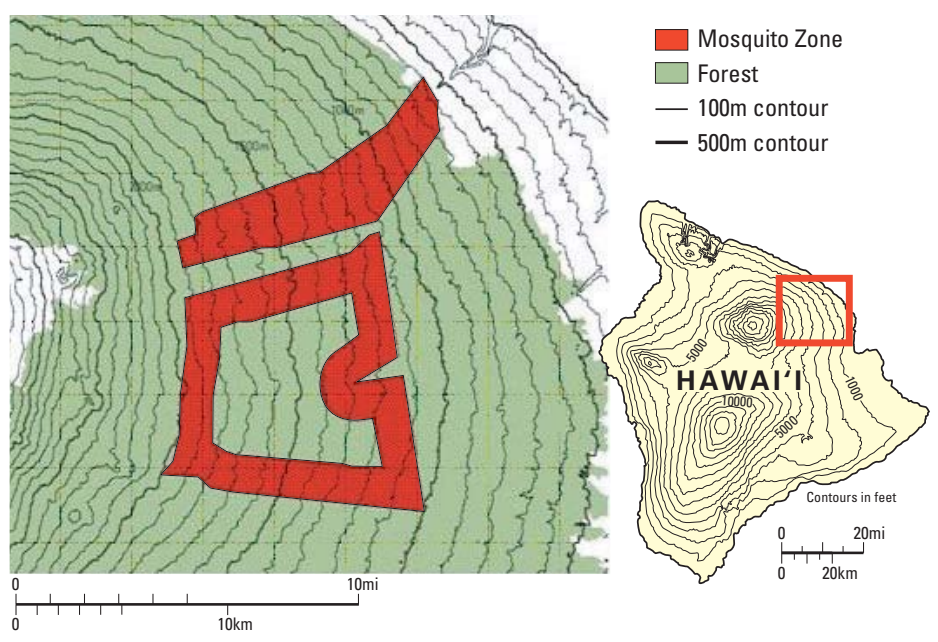

Figure 8. Given that Culex mosquitoes disperse an average of 1 mile $(1.6 \mathrm{~km})$, small tracts of protected land, such as the northern section of Hakalau Forest NWR on the Island of Hawai'i, could be inundated by mosquitoes originating outside their boundaries. As a refuge for native birds from introduced avian disease, even the largest section of Hakalau would be effectively reduced in size by 60 percent.

immigrate to parks and refuges. Removal of refuse and unnecessary structures where water accumulates can mitigate much of the problem but requires commitment and vigilance from individual land owners, communities, NGOs, as well as DOI land managers to be successful. Some DOI lands, like Hawai 'i Volcanoes National Park, may face additional challenges when considering historical structures that are protected by law. In a recent collaborative project between USGS scientists and NPS resource managers, mosquito numbers at the historic Ainahou Ranch were successfully reduced through identification of artificial habitat and its subsequent removal, modification, or treatment with a selective biopesticide.

\section{Future Threats}

New mosquito-borne diseases, like West Nile Virus (WNV), may be introduced to the Hawaiian Islands in the future. While infective migratory birds might initiate an outbreak, an even more likely scenario would be the arrival of an infective mosquito on commercial aircraft or cargo ship. Naïve native and non-native birds and abundant competent mosquito vectors (Culex quinquefasciatus and Aedes albopictus) would ensure rapid establishment and spread of WNV throughout the island chain. New mosquito species can still be introduced as well. In 2003, the first temperate mosquito species, Aedes japonicus, became established on the island of Hawai' $i$. Its ability to endure cooler temperatures may alter the present altitudinal distribution of avian pox thereby jeopardizing endangered honeycreepers inhabiting high elevation forests.

\section{Conclusions}

Native Hawaiian birds have been decimated by introduced, mosquitotransmitted avian malaria and pox. In native forests, introduced feral pigs create habitat for larval mosquitoes by feeding on tree fern trunks. Human structures provide habitat for larval mosquitoes in rural and urban areas. USGS research has shown that reducing artificial larval mosquito habitat and eliminating feral pigs effectively reduces mosquito populations in the surrounding area. Future research should be directed at determining whether reducing feral pig populations can control avian disease in native forests. Reducing larval mosquito habitat is our best hope for limiting disease transmission to native birds.

Avian disease management is essential to the preservation of native Hawaiian birds and with sound research, and commitment from land 


\section{What the Public Can Do}

Everyone can help to reduce the number of mosquitoes in their community, work place, and in forests by taking the following actions:

- Dispose of, or turn over, any containers collecting water around the yard. Abandoned tires are particularly notorious for harboring mosquitoes and should be disposed of properly.

- Cut drainage holes in old tires used around farms or playgrounds so that they cannot collect water.

- Regularly flush out birdbaths, pet water dishes, and watering troughs.

- Keep rain gutters free flowing and close, or screen off, all openings to cisterns.
- Change the water in cemetery flower vases regularly or use arrangements that do not require water.

- Keep ornamental ponds clean of debris and stock with fish (but don't put fish in natural waterways).

Fill or drain depressions in lawns or fields that regularly fill with rainwater.

- Cover or turn over boats and canoes when not in use.

- Hunt feral pigs.

- When other means of reducing larval mosquito habitat are not possible, use monthly applications of Bacillus thuringiensis israelensis in strict accordance with the label.

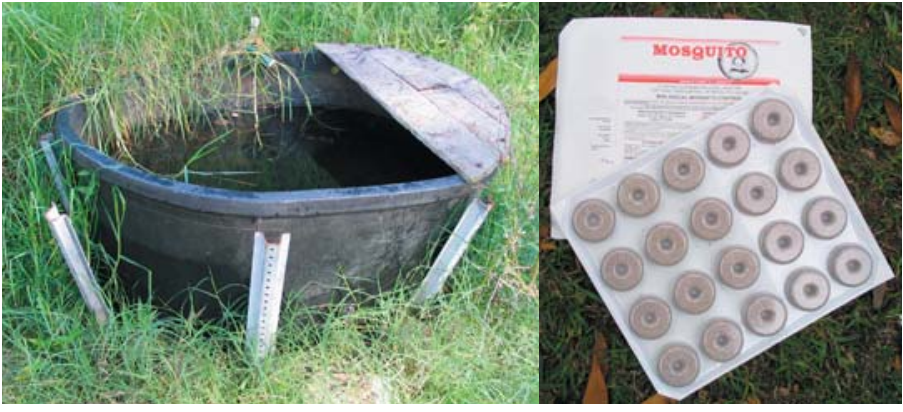

Figure 9. Manmade water impoundments (such as horse troughs) were the main larval mosquito habitat at Ainahou Ranch. When standing water could not be completely eliminated, mosquito larvae were reduced with monthly applications of the biopesticide Bacillus thuringiensis israelensis.

management agencies and the general public, the impact of disease can be minimized. Control of mosquito-borne disease, however, must be coordinated over broad landscapes and will necessitate the cooperation of individuals, communities, and governmental agencies.

Resources should be directed into integrative mosquito control and the development of long-term disease management strategies. Source reduction and mosquito-proof design of infrastructure should be considered in avian disease management. Lands acquired for conservation should focus on inholdings and adjacent lands to minimize edge effects of unmanaged land.

Direct source reduction through removal and modification of artificial containers and impoundments, and indirect source reduction through the elimination of feral pigs, can successfully reduce and potentially eliminate mosquito populations.

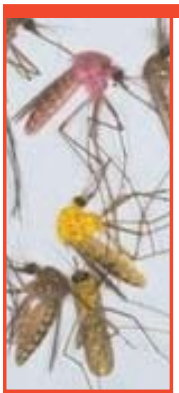

\section{For additional information contact:}

Dr. Dennis A. LaPointe, Ecologist

Phone: (808) 967-8119

Email:dennis_lapointe@usgs.gov

\section{Photo Credits:}

USGS file photographs, unless otherwise noted.

\section{Partners and Collaborators}

- US Fish and Wildlife Service

- National Park Service

- The Nature Conservancy

- Smithsonian Institution

- National Science Foundation

- Hawai'i Department of Land and Natural Resources

- Hawai'i Department of Health

- University of Hawai'i at Mānoa, Pacific Cooperative Studies Unit

- University of Hawai'i at Hilo, Hawai'i Cooperative Studies Unit

\section{Recommended Reading}

Ahumada, J.A., D.A. LaPointe and M.D. Samuel. 2004. Modeling the population dynamics of Culex quinquefasciatus (Diptera: Culicidae), along an elevational gradient in Hawai'i. Journal of Medical Entomology 41: 1157-1170.

Atkinson, C.T., K.L. Woods, R.J. Dusek, L.S. Sileo and W.M. Iko. 1995. Wildlife disease and conservation in Hawai' $i$. Pathogenicity of avian malaria (Plasmodium relictum) in experimentally-infected 'I'iwi (Vestiaria coccinea). Parasitology 11: S59-S69

Jacobi, J.D. and C.T. Atkinson. 1995. Hawai'i's endemic birds. IN: Our Living Resources: a Report to the Nation on the Distribution, Abundance and Health of U.S. Plants, Animal, and Ecosystems. E.T. LaRoe, G.S. Farris, C.E. Puckett, P.D. Doran and M.J. Mac, eds. U.S. Department of Interior, National Biological Service, Washington, D.C. pp. 376-381.

Kilpatrick, A. M., Y. Gluzberg, J. Burgett, and P. Daszak. 2004. Quantitative risk assessment of the pathways by which West Nile virus could reach Hawai'i. EcoHealth 1(2): 205-209.

LaPointe, D.A., M.L. Goff and C.T. Atkinson. 2005. Comparative susceptibility of introduced forest-dwelling mosquitoes in Hawai'i to avian malaria, Plasmodium relictum. Journal of Parasitology 91: $843-849$. 